\title{
HIPÓTESES DE INFRAESTRUTURA VERDE PARA CRIAÇÃO DO PARQUE LINEAR BRÁS-LAPA
}

\author{
Giorgia Yoshiko Rossignolo Suzumura* \\ * Arquiteta e urbanista pela FAU-USJT; Licenciatura pela Fatec-SP; \\ Professora de Edificações do IFSP - campus Itapetininga. \\ giorgiayrs@gmail.com
}

\begin{abstract}
RESUMO
Este artigo tem por objetivo analisar a ligação férrea feita atualmente entre as áreas do Parque da Luz e Parque da Água Branca, e discutir a proposta de intervenção nesta, próxima ao Parque da Água Branca, a qual, como consta no Plano Diretor de São Paulo, visa um melhoramento viário, propondo enterrar toda a linha férrea e construir sobre esta uma avenida para os automóveis, com canteiros centrais e laterais sendo considerados "parques lineares", com ciclovias.

O objetivo principal deste artigo é analisar e esclarecer os conceitos de projeto de parque linear, visando o desenho ambiental, o projeto de parque sustentável e a mobilidade urbana sustentável, além de identificar os problemas encontrados atualmente no local, em visita executada pelos alunos da disciplina de Projeto Sustentável do Programa de Pós-Graduação da Faculdade de Arquitetura e Urbanismo da Universidade de São Paulo, em agosto de 2012.

O artigo visa direcionar hipóteses de infraestrutura verde para criação do parque linear Brás-Lapa, desconsiderando as diretrizes que não condizem com os conceitos abordados no âmbito de projeto sustentável, principalmente aquelas levantadas em pesquisa, pelo que relata a Operação Urbana da Água Branca e Lapa - Brás.

O enfoque é recuperar o local, propondo mudanças no projeto de intervenção. Pretende-se propor hipóteses possíveis, como metodologias para dirimir diretrizes de implantação de um parque linear na área do trilho do trem, tendo em vista os conceitos abordados em aula, sendo estes o de projeto, com ênfase no desenho ambiental, de parque linear com mobilidade urbana sustentável, entre o Brás e a Lapa, interferindo na linha férrea, e considerando que a melhor proposta estabelece que o trilho deverá ser modificado, ora estando subterrâneo, ora estando em nível.
\end{abstract}


Palavras-chave: Parque Linear Brás-Lapa, parque linear sustentável, mobilidade urbana, mobilidade urbana sustentável, infraestrutura verde.

\title{
HYPOTHESIS OF GREEN INFRASTRUCTURE FOR CREATION OF THE LINEAR PARK BRÁS-LAPA.
}

\begin{abstract}
This article aims to analyze the current railroad connection between the areas of Parque da Luz and Parque da Água Branca, as well as to discuss the proposal of intervention there, close to Parque da Água Branca, which as stated in the Master Plan of São Paulo, targets the improvement of roads, proposing to bury the whole railway and to build on it an avenue for cars with medians and sides, to be considered "linear parks" with bike lanes.
\end{abstract}

The main target of this study is to analyze and clarify the project concepts of a linear park, focusing the environmental design, the project of a sustainable park and sustainable urban mobility, as well as to identify the problems currently found at that site by visits of students of the subject Sustainable Project of post-graduation program at Faculty of Architecture and Urbanism at University of São Paulo in August 2012.

The study also aims to focus the hypothesis of green infrastructure to develop the Linear Park Brás - Lapa, disregarding the guidelines that are not consistent with the concepts discussed in the context of sustainable project, especially those raised in research by reporting the Operation Urban Água Branca and Lapa - Brás.

The approach is to recover the site, proposing changes in the intervention project, by the proposition of feasible hypothesis as methodologies to resolve implementation guidance of a linear park in the area of the train rails targeting the concepts covered in class, i.e., the linear park project with sustainable urban mobility aiming the environmental design between Lapa and Brás, and interfering with the railroad, considering that the best proposal is that which the rails are to be moved, sometimes being underground, sometimes in level.

Key words: Linear Park Brás - Lapa; Sustainable Linear Park; Urban Mobility; Sustainable Urban Mobility; Green Infrastructure. 


\section{INTRODUÇÃO}

Este artigo é resultado de um trabalho feito para a disciplina de Projeto Sustentável, no Programa de Pós-Graduação da Faculdade de Arquitetura e Urbanismo da Universidade de São Paulo, ministrada pela professora doutora Maria de Assunção Ribeiro Franco.

Como proposta da disciplina, primeiramente foram estudadas algumas referências bibliográficas, para melhor entendimento sobre os diversos assuntos abordados no âmbito do projeto sustentável. Com isso, foram feitas, em aula, algumas apresentações sobre os levantamentos bibliográficos analisados e, sendo assim, houve um maior e melhor entendimento sobre essa linha de pesquisa.

Após a análise dos conceitos bibliográficos, dois estudos de caso foram levantados pela professora, para que os alunos da disciplina pudessem analisar e propor medidas de melhorias para estes, sendo, o primeiro, o Parque da Luz, e o segundo, o Parque da Água Branca, visando principalmente sua interligação pela linha férrea.

Como se sabe, a Operação Urbana Água Branca e Lapa - Brás propõe a integração entre as estações por um "parque linear", sendo este melhor definido como uma avenida com canteiros centrais, que fará a ligação entre os bairros, por onde hoje passa a linha férrea, sendo que esta ficará subterrânea à avenida proposta.

Um dos principais motivos para a idealização deste artigo foi analisar essa proposta, relatar, criticar e identificar os impactos por essa intervenção, mostrando que pode haver uma proposta melhor, mais sustentável, seguindo os conceitos assimilados ao longo da disciplina estudada, e privilegiando, sobretudo, o pedestre, o meio ambiente e a locomoção.

Com o estudo da proposta da Operação Urbana da Água Branca, neste artigo, a pesquisadora faz uma análise e propõe hipóteses de um parque linear sustentável entre o Brás e a Lapa, pela linha férrea, que ora pode ser subterrânea, ora não, visando a mobilidade urbana, a preocupação com o entorno e, principalmente, propondo que esse parque linear siga os conceitos do desenho ambiental e do projeto 
sustentável, para garantir a melhoria na qualidade de vida dos moradores, do entorno e da população que usará esse local.

\section{Localização}

A área descrita a seguir é a interligação entre os bairros Brás e Lapa, pelo percurso da linha férrea. O mapa a seguir mostra a ligação entre o Parque da Luz e o Parque da Água Branca, que foram o foco inicial, como estudo da disciplina de Projeto Sustentável no programa de Pós-Graduação da Faculdade de Arquitetura e Urbanismo da Universidade de São Paulo.

Como parte do estudo, foi verificado que, no Plano Diretor da cidade de São Paulo, mais precisamente na Operação Urbana da Água Branca, há uma proposta de intervenção e interligação dessas áreas, visando um melhoramento, na parte do sistema viário e da drenagem, de onde atualmente se encontra a linha de trem da CPTM - Companhia Paulista de Trens Metropolitanos. O que o plano propõe é que a locomoção entre os bairros seja feita por avenidas no nível da rua, por modais urbanos, $e$, consequentemente, a linha férrea correria subterraneamente a essa avenida, e a drenagem seria feita por canteiros centrais e laterais.

No mapa abaixo pode-se verificar a distância entre os dois parques, muito conhecidos e frequentados na cidade, tendo sido ambos analisados pela equipe de pós-graduação. $A$ distância entre o Parque da Luz e o Parque da Água Branca é de aproximadamente quatro quilômetros. Como o objetivo deste artigo é analisar as diretrizes estabelecidas pela Operação Urbana Água Branca e Lapa - Brás e propor melhores hipóteses de infraestrutura verde, a pesquisadora ampliou a área de estudo do bairro da Lapa até o Brás, aumentando, assim, aproximadamente oito quilômetros à distância mencionada anteriormente.

Este aumento na área de estudo se dá, principalmente, pela visão da pesquisadora, em querer analisar o que está sendo proposto na Operação Urbana Lapa - Brás, e também correlacionar o que estuda e pesquisa, sem esquecer o grande volume de usuários e transeuntes que passam diariamente pelos trens, principalmente na estação Brás, e também considerando a interligação desta estação com outros modais, e sua relação com o terminal da Lapa. 


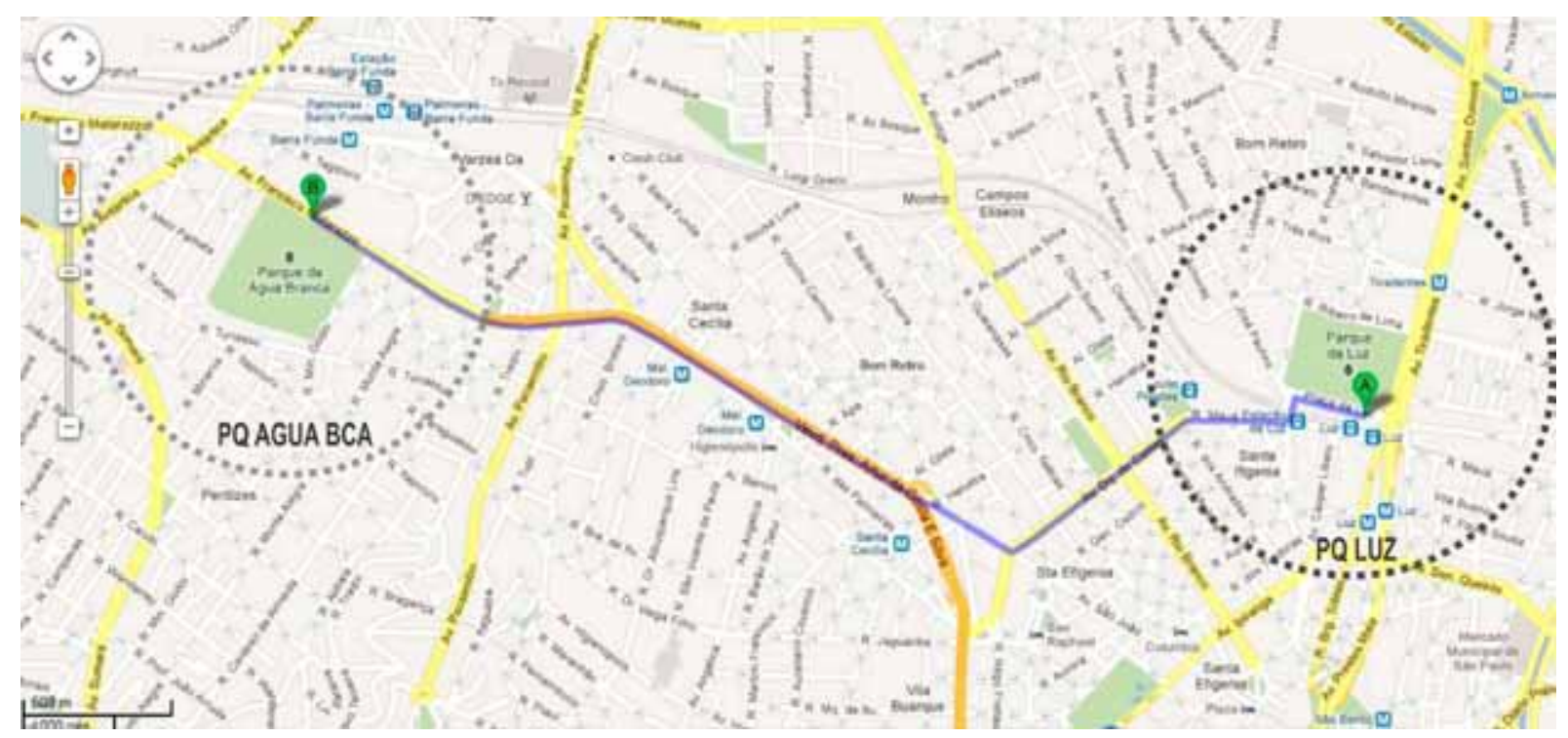

Figura 01: Trajeto entre Parque da Água Branca e Parque da Luz. Mapa: Franco (2012)

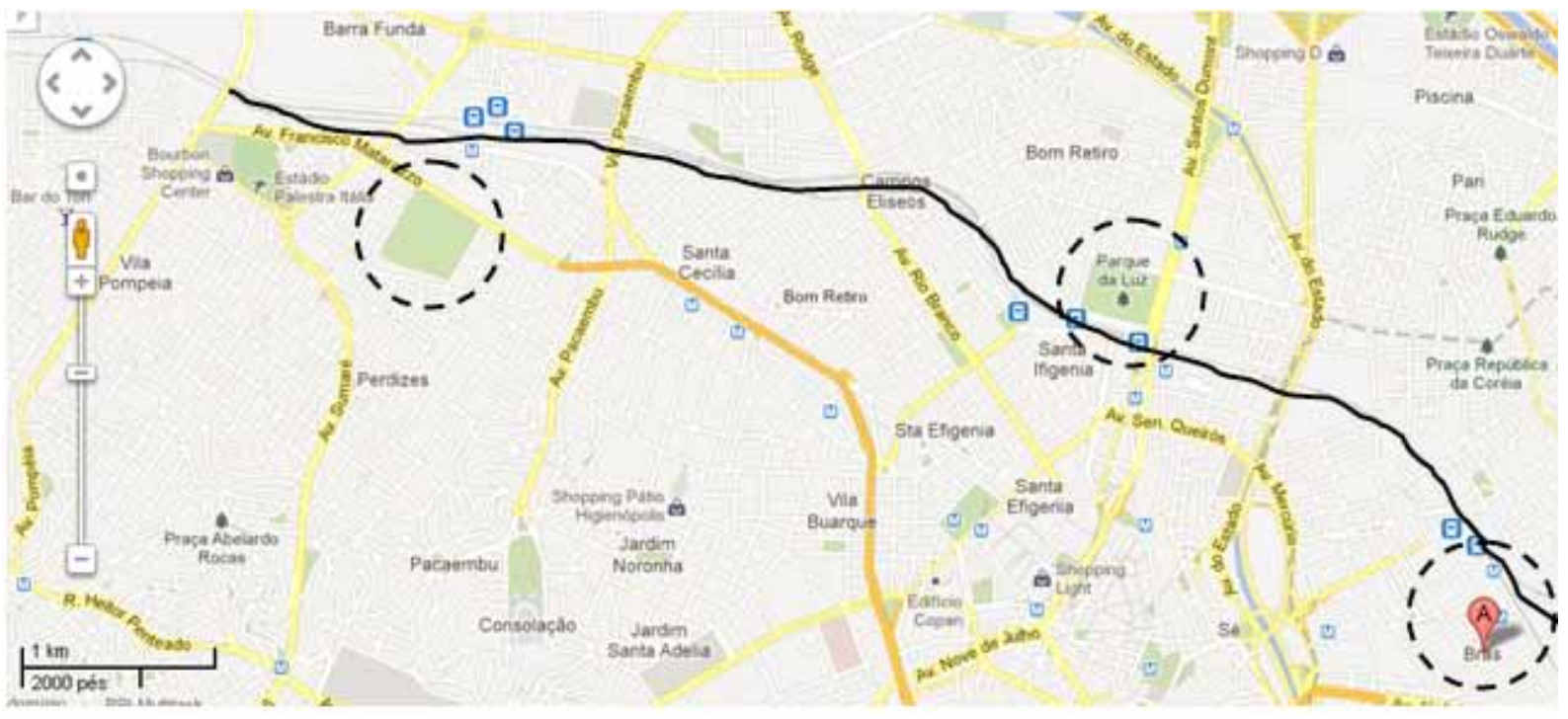

Figura 02: Linha férrea entre Barra Funda, Luz e Brás. Mapa: googlemaps.com (2012)

O mapa acima mostra a relevância do trajeto entre esses pontos, considerando ainda os parques próximos e outros equipamentos.

O percurso entre as zonas Leste e Oeste é intenso. Como transporte para fazer essa ligação, temos as linhas de trens, metrôs e o sistema viário, e tudo isso ainda é muito complicado, pois não dá assistência suficiente, porque o sistema de transporte de São Paulo é ineficiente, ocasionando muito trânsito, problemas ambientais e, sobretudo, problemas relacionados à vida da população. 


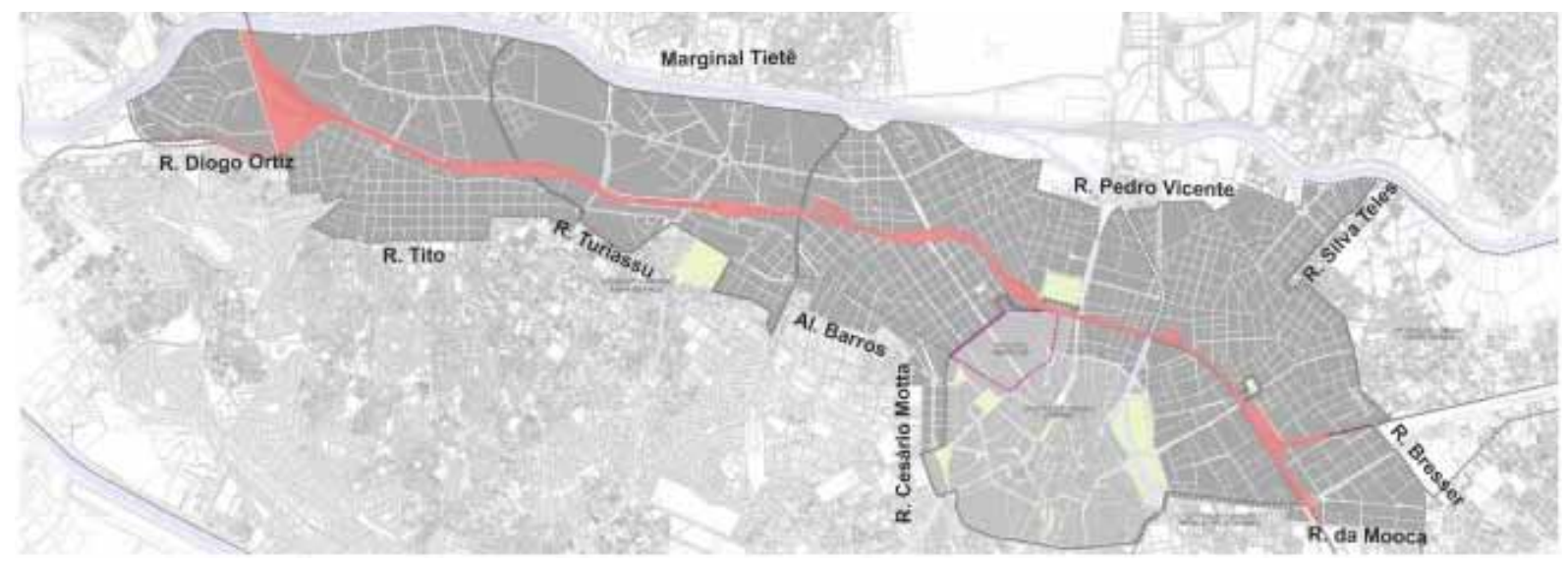

Figura 03: Mapa da área de abrangência da Operação Urbana Lapa - Brás. Foto: http://www.diarioda lapa.com.br/noti_lapa/lapabras_edital911.htm

De acordo com o projeto da Operação Urbana Lapa - Brás, a pista ferroviária será realizada em um sistema subterrâneo, ligando a Lapa ao Brás, numa extensão de aproximadamente 12 quilômetros. Na superfície, o projeto prevê uma via diferenciada, com parques e ciclovias.

Segundo a imagem abaixo, que saiu no portal do jornal O Estado de S. Paulo, um dos objetivos que está por trás da Operação Urbana Lapa - Brás é possibilitar a demolição do "Minhocão", o Elevado Costa e Silva, o tão polêmico sistema viário que faz a ligação do eixo Leste - Oeste.

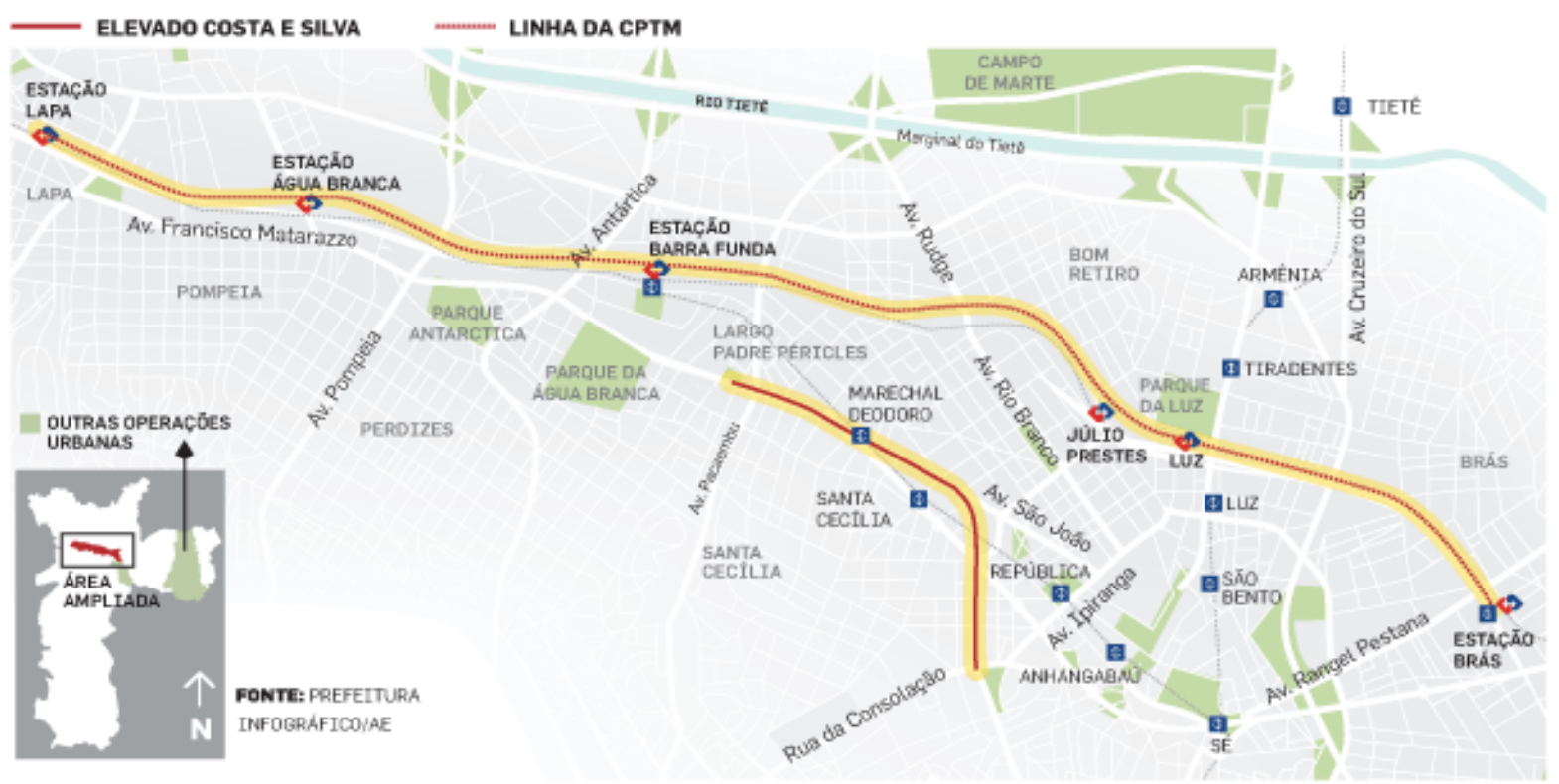

Figura 04: Operação Urbana Lapa - Brás. Foto: http://www.estadao.com.br/noticias/cidades, prefeituraquer-tunel-de-12-km-para-circulacao-de-trens-entre-lapa-e-bras 
Com a execução da avenida sobre o sistema ferroviário subterrâneo, relatam que meIhoraria o trânsito e, com isso, seria viabilizada a demolição do viaduto.

Mas não é só essa a questão. Até onde vão as intenções dos governantes?

Até onde eles estão realmente pensando na população?

Até onde as diretrizes propostas no projeto seguem realmente o que eles relatam como diagnósticos para melhorar a situação local?

Sabe-se da evolução e da importância da área estudada, principalmente quando, em observação in loco, se notam vários equipamentos ao longo do trecho analisado.

\section{Críticas à Operação Água Branca e Lapa - Brás}

egundo o que se pode observar no documento da Operação Urbana Lapa - Brás, seu objetivo declarado é o de promover o desenvolvimento da região de modo equilibrado, dando condições para que as potencialidades regionais sejam devidamente efetivadas.

Até aí, os objetivos que constam na Operação Urbana Lapa - Brás demonstram uma intenção favorável de mudança e de possíveis requalificações do local, visando à meIhoria e reestruturação do ambiente e entorno.

Continuando a análise da Operação Urbana Lapa - Brás, no documento se afirma que deve haver a superação da barreira metroferroviária e a reurbanização de sua orla, de modo a ser o principal elemento estruturador e ordenador do território, do ponto de vista urbanístico geral, abrangendo a melhoria da mobilidade, da acessibilidade, a reconstituição do tecido urbano pela continuidade do sistema de circulação, a possibilidade de ocupar ordenadamente áreas vazias ou subutilizadas, no aumento da permeabilidade do solo, da cobertura vegetal, dos espaços públicos de convívio e lazer.

A imagem abaixo mostra que a linha férrea de 12 quilômetros entre a Lapa e o Brás foi enterrada, e sobre esta foi proposta uma avenida com canteiros centrais. 


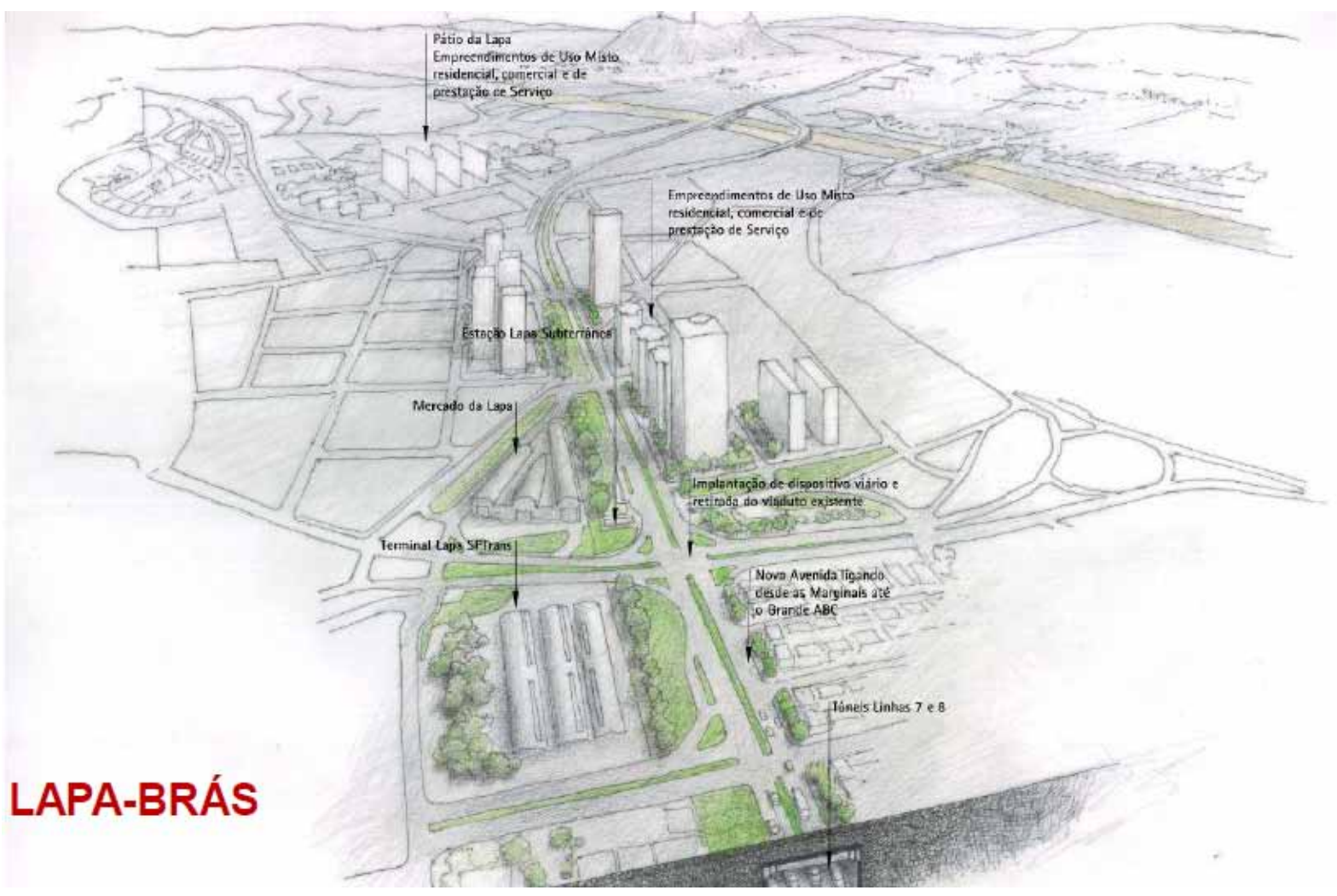

Figura 05: Proposta da Operação Urbana - Avenida com canteiros centrais e laterais sobre a linha férrea enterrada. Foto:http://www.ideosfera.ggf.br/wp-content/uploads/2011/06/CPTM-Opera-UrbanaLapa-Br\%C3\%A1s-01.png

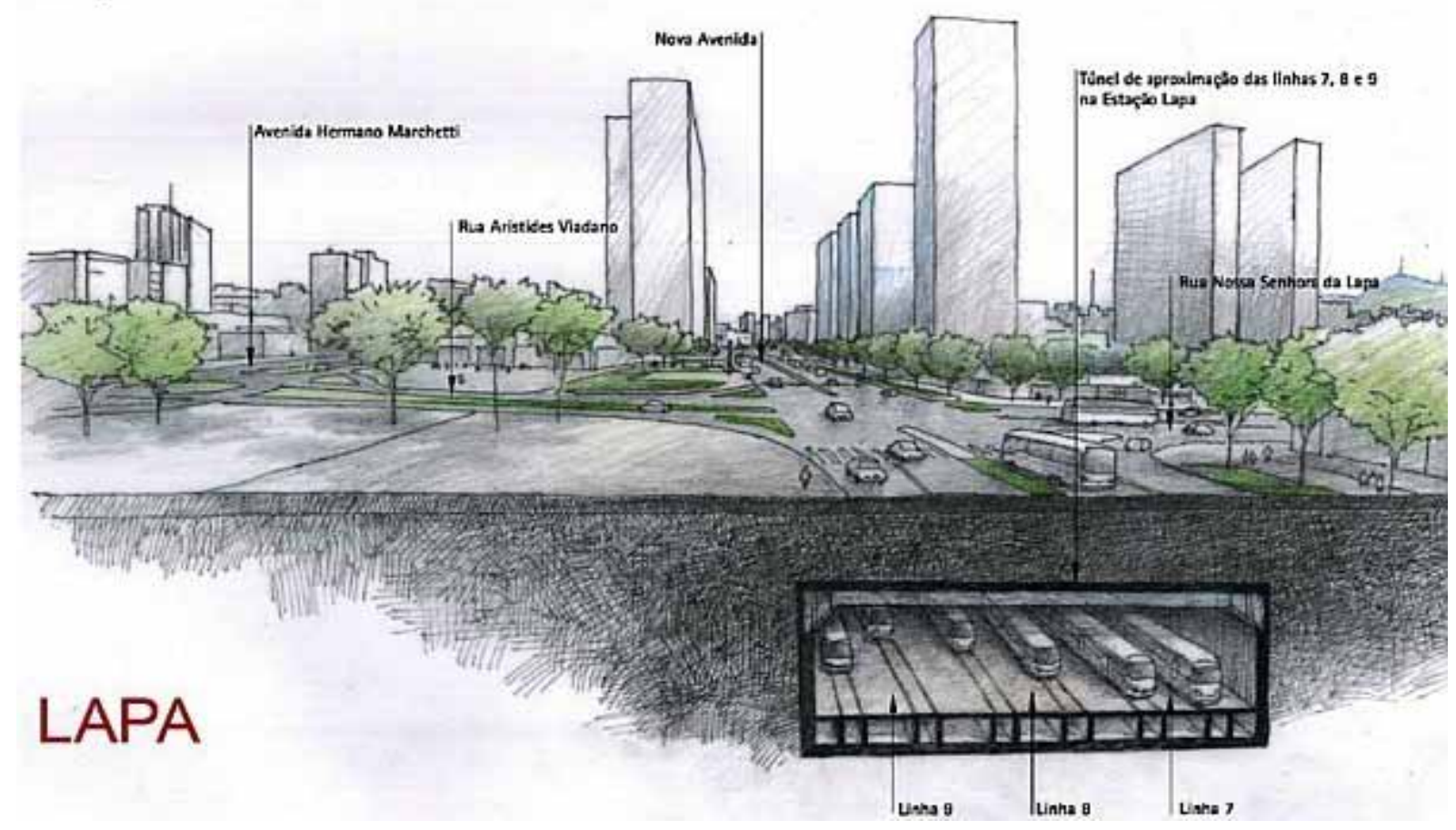

Figura 06: Proposta da Operação Urbana Lapa - Brás - Linha férrea totalmente enterrada nos seus $12 \mathrm{~km}$ de extensão. Foto: http://www.estadao.com.br/fotos/NO_TEXTlapa_600.jpg 
Como proposta específica, a operação propõe o rebaixamento das calhas ferroviárias, desde as proximidades da Lapa, até as proximidades do Brás. E, como objetivos específicos, foram determinados os seguintes itens, que serão criticados sob o ponto de vista da pesquisadora:

Implantar um conjunto de melhoramentos viários visando ligações de longo percurso;

Verificando-se a imagem que mostra a situação pretendida e a proposta da operação urbana, nota-se que uma avenida não é o melhor método de sistema viário para ligação de longo percurso, mantendo ainda a linha férrea totalmente subterrânea.

Melhorar os sistemas de macro e micro drenagem, para diminuir os problemas de inundação ocasionados pela deficiência das redes e galerias existentes;

Como se melhora o sistema de drenagem e se propõe diminuir os problemas de inundação ocasionados pela deficiência das redes e galerias, com uma proposta de deixar a linha férrea totalmente subterrânea durante o seu percurso de 12 quilômetros entre a Lapa e o Brás? E, além disso, ao longo do percurso, sobre a linha férrea, propõe-se uma avenida com canteiros centrais e laterais, que sirvam de "áreas verdes" e ciclovias para os pedestres. Lembrando que esses canteiros centrais não fazem parte da concepção de um parque linear, não se trata de uma área toda permeável, portanto não é a melhor diretriz para propor com o objetivo de melhorar o sistema de drenagem na cidade.

\section{Implantar espaços públicos;}

De acordo com o projeto previsto pela Operação Urbana, osespaços públicos a serem implantados serão segmentados pelos canteiros e ciclovias, entre as avenidas e ruas adjacentes.

\section{Implantar equipamentos de interesse da comunidade;}

Os equipamentos só poderão ser implantados nos espaços públicos, na sua maioria, segmentados e fragilizados. 


\section{Promover a reestruturação e a requalificação urbanística e ambiental do território;}

Deveria haver um melhor planejamento e desenvolvimento de proposta para a área, em que reestruturar e requalificar o local não signifique apenas enterrar aquilo que consideram como um problema, no caso, a linha férrea, e colocar uma avenida sobre a mesma, para melhorar o tráfego no "minhocão" e, assim, possibilitar sua demolição. E, como proposta de áreas verdes e "permeáveis" sobre a ferrovia, contar com canteiros centrais e laterais para fazer o papel de "parque linear", com proposta de ciclovia e equipamentos para a população.

Integrar os tecidos atualmente segregados pelo sistema sobre trilhos, ampliando as conexões entre os fluxos de circulação;

A avenida continuará fazendo o papel de divisora entre um lado e o outro, criando ainda cruzamentos em nível, trazendo mais problemas no sistema viário e mantendo o problema que queriam eliminar, só que de outra forma, com outro tipo de sistema de transporte.

Aumentar e promover a criação, ampliação e requalificação de áreas verdes e espaços livres de uso público, aumentando a permeabilidade e área verde e locais de convivência e relações sociais;

Para aumentar e promover a criação, ampliação e requalificação de áreas verdes e espaços públicos, antes de tudo eles devem ser voltados para a população, com equipamentos de lazer, áreas não fragmentadas, áreas que tenham conexão com o trajeto dos pedestres. Para serem permeáveis, não podem ser executadas sobre uma linha férrea, e sim mantidas em solo. Tem dee se tratar de uma infraestrutura verde para a cidade, e não apenas canteiros ao longo de uma avenida, dizendo que se preocuparam, e pincelando verdes sobre o solo, ao longo da avenida.

A nova via proposta deverá ter caráter estrutural, com uso lindeiro intenso, cruzamentos em nível, passeios e canteiros centrais amplos, que lhe confiram características de urbanidade e permanência, e não apenas de sistema de passagem.

Pois bem, isso é intervenção que podemos chamar de infraestrutura verde? Isso é implantar um conjunto de melhoramentos viários, visando ligações de longo percurso? 
Diversos canteiros com plantas e jardins estão espalhados por toda a sua extensão, incluindo o Sun Deck Water Feature que libera água pelo chão, nos dias mais quentes, para refrescar os pés de quem está passeando pelo parque. Bancos de madeira, espreguiçadeiras e guarda-sóis também são encontrados facilmente, e são os lugares mais procurados.

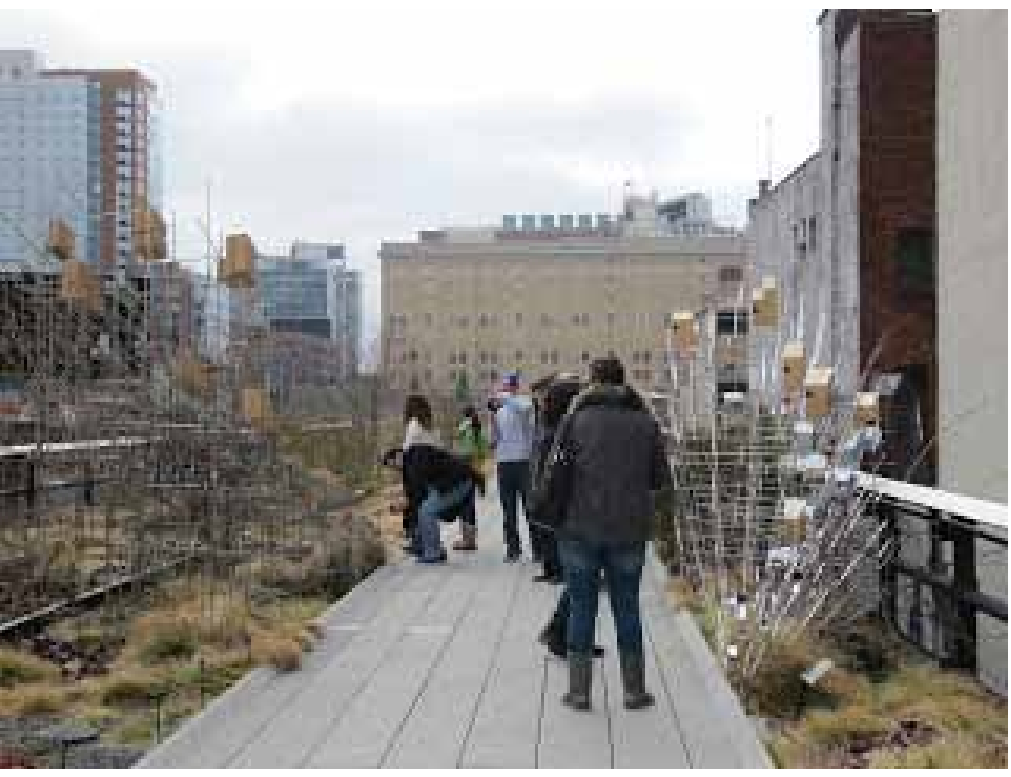

Figura 08: Estruturas para alimentação de pássaros.

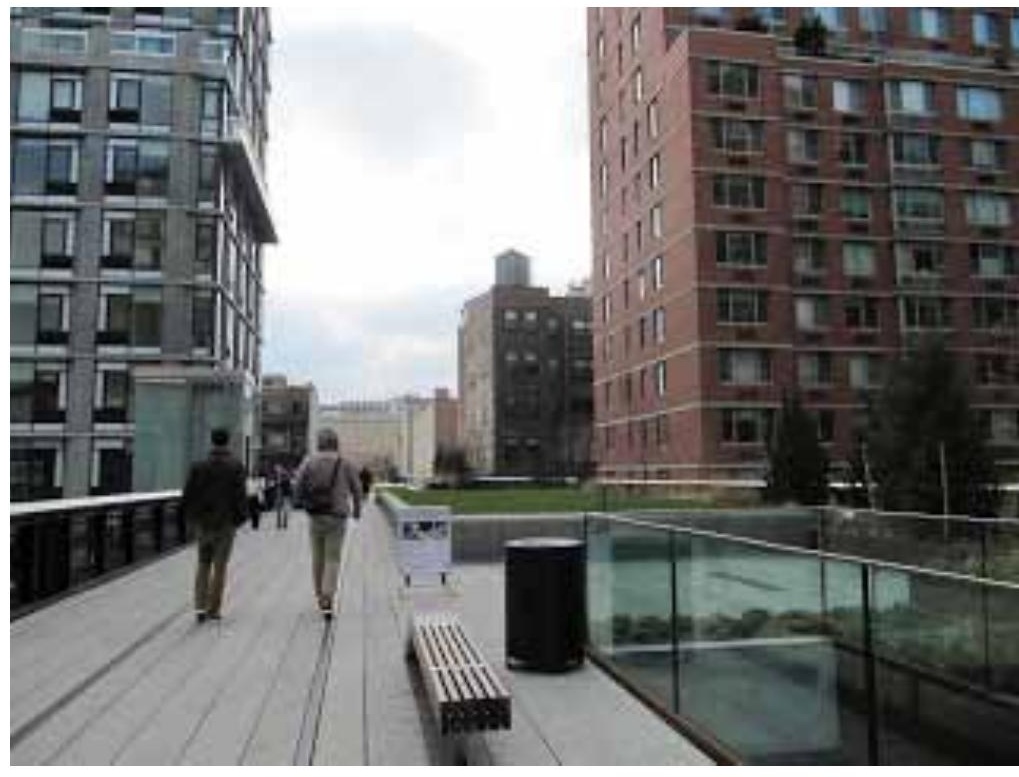

Figura 09: Visão do parque entre os prédios.

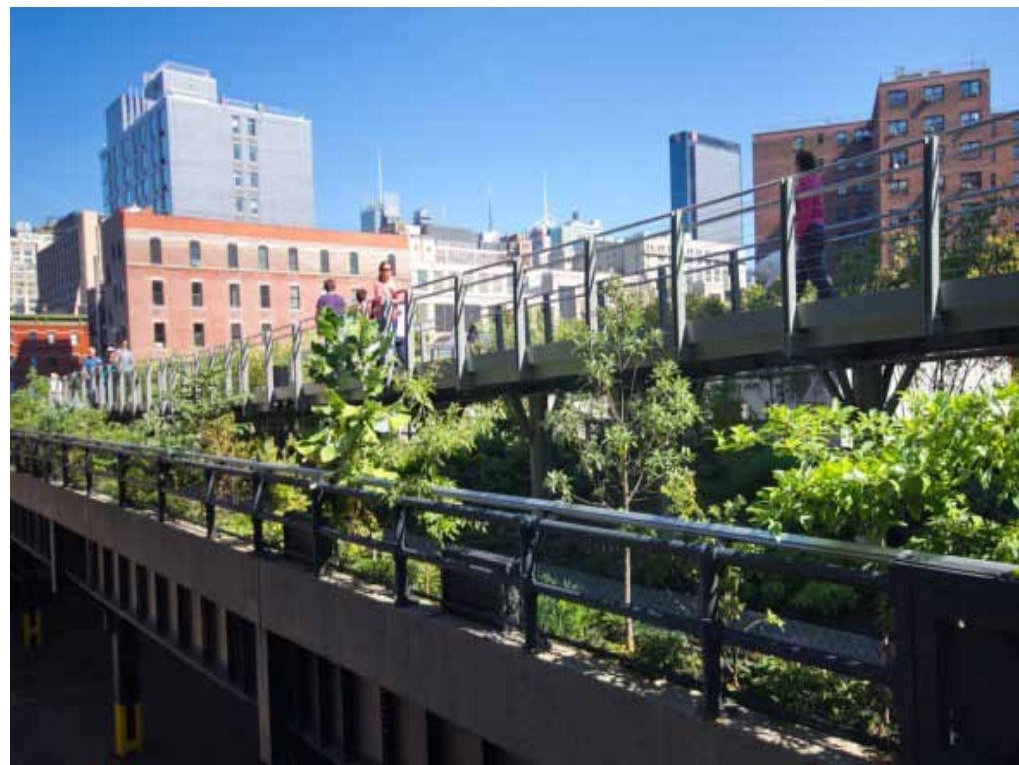

Figura 11: Vegetação nas alturas.

Figura 10: O trilho ainda faz parte da paisagem.

Fotos: http://sementesustentavel.blogspot.com.br/2012/04/um-parque-nos-trilhos-do-trem.html 
A ideia de se utilizar a estrutura do trem que ia ser demolida para construir um parque é excelente e inovadora. Isso é sustentabilidade, é reutilizar e ainda trazer um bem maior à comunidade.

\section{Parque Ecológico no Peru}

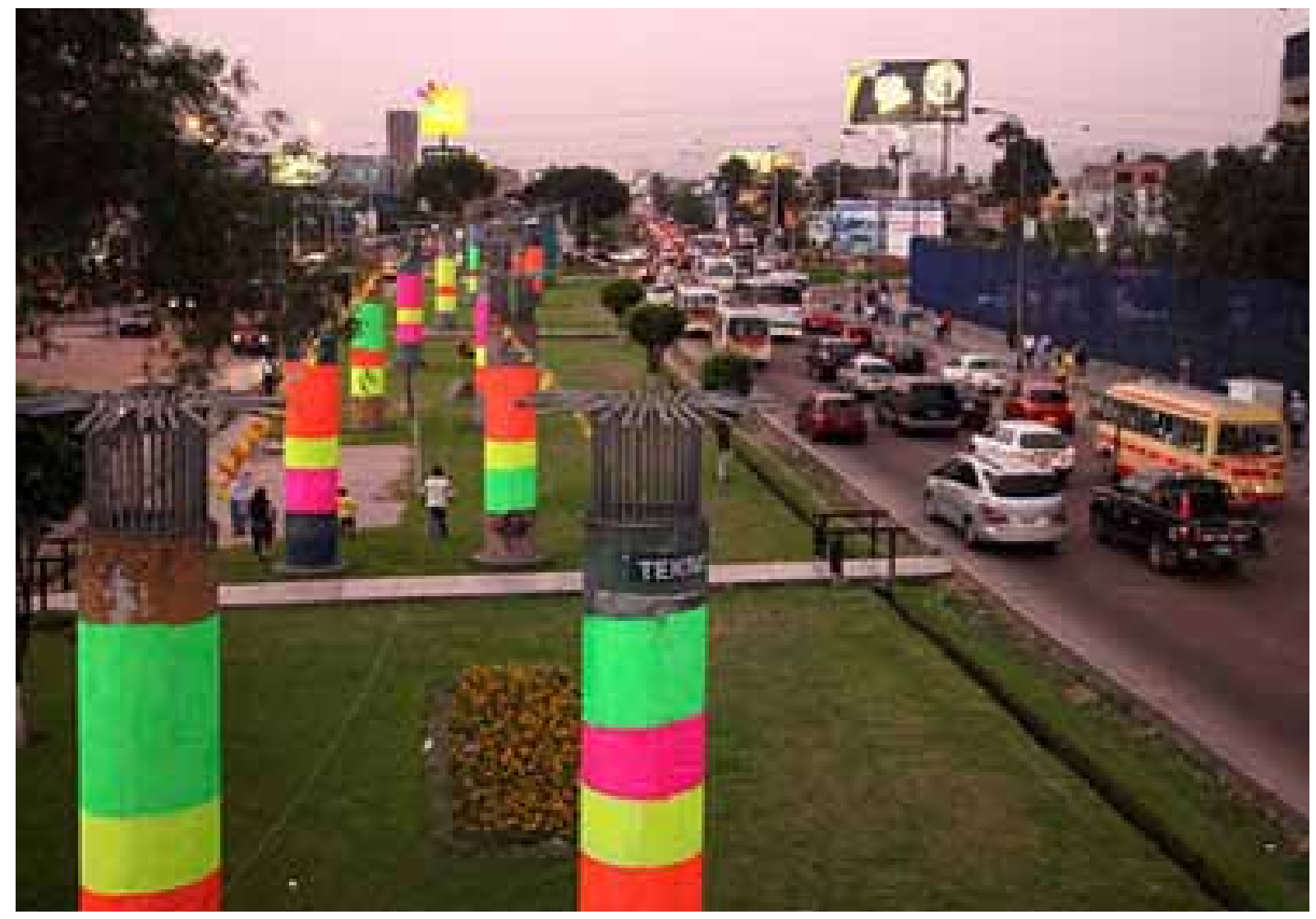

Figuras 12. Fotos: http://blog.naturaekos.com.br/ruinas-de-trilho-de-trem-viram-parque-ecologico-no-peru/

As colunas da obra, que nada seguravam, pareciam imitar os filmes de ficção e, na criatividade da população, surgiu o trem imaginário. Os moradores da região já haviam apelidado as ruínas de Trem Fantasma. A construção dos trilhos foi abandonada no meio, e seus restos foram deixados de lado. O grupo Basurama viu ali uma oportunidade, e construiu um parque ecológico de diversão para adultos e crianças.

A nova área de lazer, cujos brinquedos são feitos de materiais recicláveis, levou o nome das lendas: Parque do Trem Fantasma. A ideia principal foi criar e trabalhar, nos espaços públicos, para as pessoas, e não para os meios de transporte. 


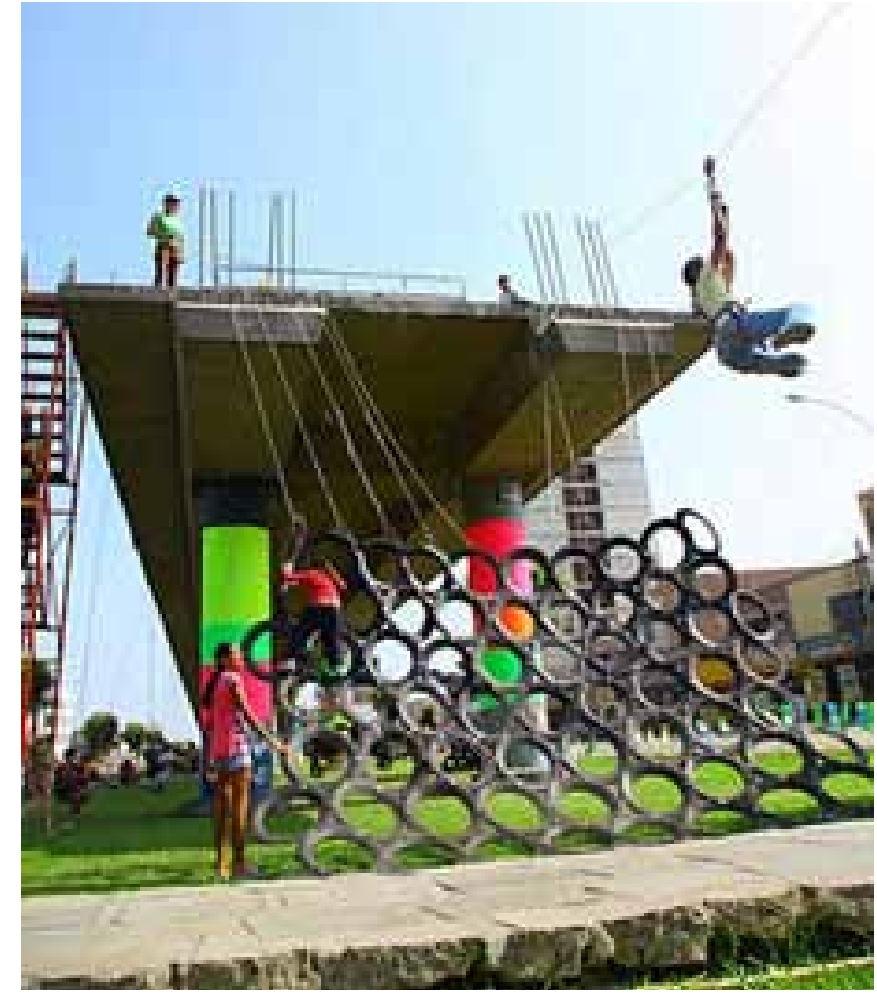

Figuras 13. Fotos: http://blog.naturaekos. com.br/ruinas-de-trilho-de-trem-viram-parque-ecologico-no-peru/

\section{Railroad Park - Birmingham - Alabama}

O Railroad Park, no Alabama, é um parque que conta com 19 hectares, no centro de Birmingham, e que celebra o patrimônio industrial e artístico da cidade.

A equipe que projetou o parque passou cinco anos trabalhando intensamente, numa parceria público / privada, para construir este parque central. A empresa responsável pelo projeto conseguiu uma grande equipe de consultores, incluindo arquitetos, paisagistas e engenheiros, que trabalharam e tiveram sempre como tema, constante em todo o projeto, as linhas ferroviárias inseridas no terreno, como foco principal do parque.

O terreno do parque é um antigo armazém, e o parque é formado com materiais recuperados de usos históricos do local.

Além de a sustentabilidade ser encontrada na concepção da sua construção, pelos materiais utilizados na obra, também há a captação de água pluvial, com a proposta de criação de um grande reservatório para irrigação, que também descarrega, através de um fluxo, a uma série de lagoas, como uma fonte de verão, que trabalha com a reutilização da água e como "piscinões", para contenção da água das chuvas nos períodos de cheias. 

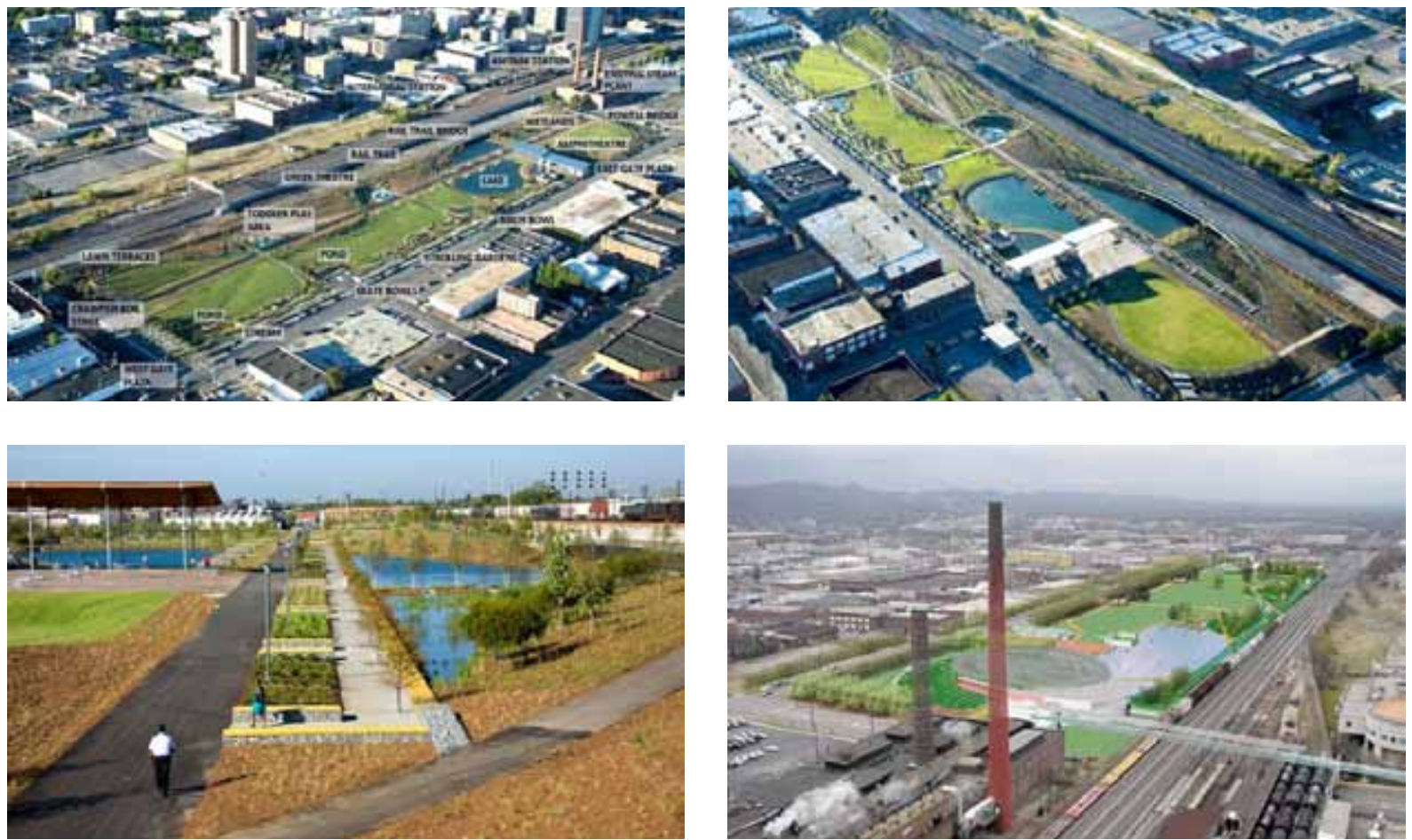

Figuras 14, 15, 16 e 17: Imagens do Railroad Park.

Fotos: http://www.railroadpark.org/ e http://www.tomleader.com/

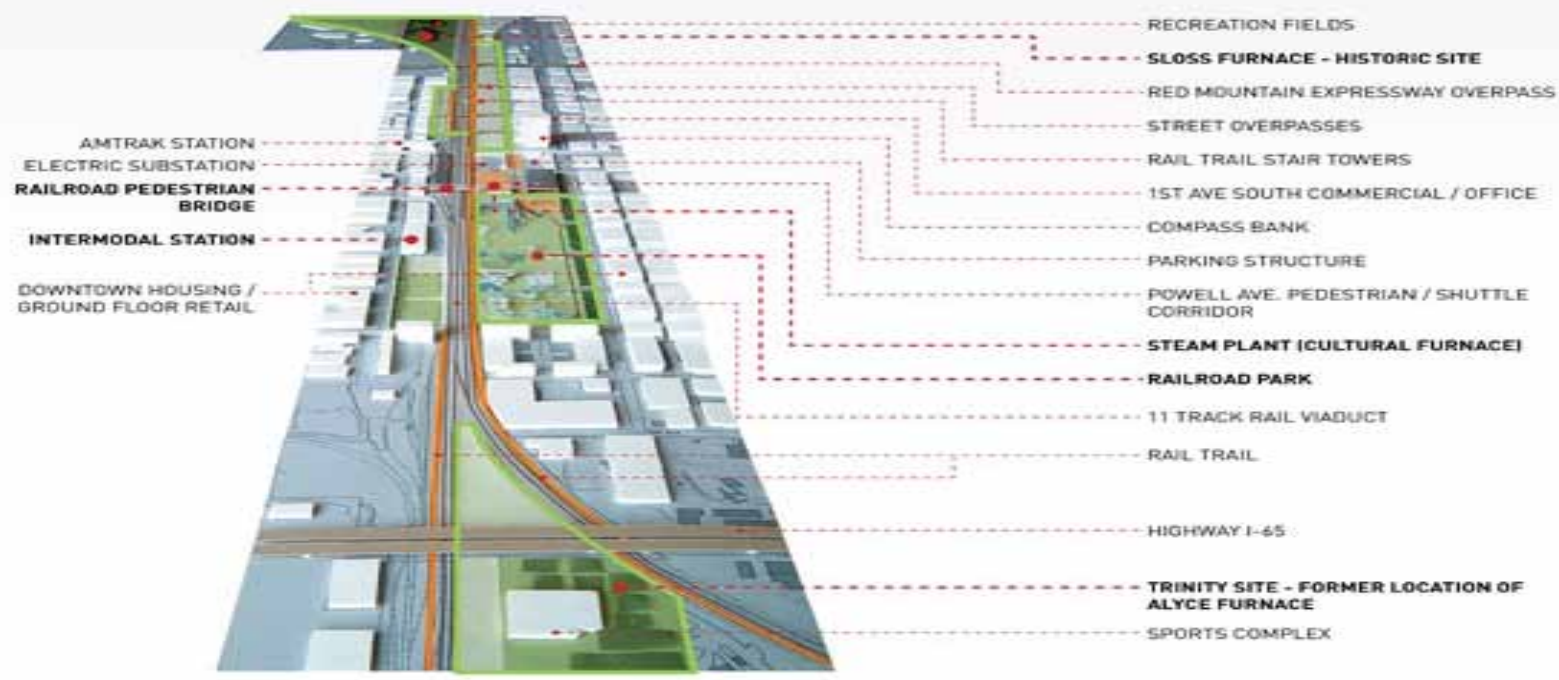

Figura 18: Linha férrea e disposição do Railroad Park. Foto: http://www.tomleader.com/

Tom Leader, arquiteto de Berkeley, na Califórnia, que liderou o projeto do parque, disse que Birmingham representou um desafio particular. Parques urbanos muitas vezes são construídos às margens de um rio, mas Birmingham não tem um rio, e sim um trilho, disse ele. 
O parque é formado por várias lagoas. Uma praça aberta foi construída, com mesas e cadeiras protegidas por uma vasta cobertura. Um pequeno parque infantil, equipamentos de ginástica e um pequeno parque de skate foram adicionados, mas grande parte da área cultivada foi reservada como espaço verde, para utilização dos visitantes.

O objetivo principal do parque, ao ser criado, era de ser uma ponte entre o Southside e o centro, além de a esperança para este parque ter sido a de que as coisas iriam se desenvolver em torno dele.

De muitas maneiras, Railroad Park é o clássico oásis verde multiuso em um ambiente urbano, com gramados, fontes, trilhas para caminhada, um riacho e muito mais. Mas, de certa forma, o parque se distingue, é um paraíso de trainspotter. Os visitantes podem sentar e relaxar, em uma série de colinas ao longo do viaduto, observando de perto os trensque deslizam.

\section{Mobilidade Urbana Sustentável}

Mobilidade é o grande desafio das cidades contemporâneas, em todas as partes do mundo. A opção pelo automóvel parecia ser a resposta eficiente do século $X X$ à necessidade de circulação e locomoção, e isso acabou levando à paralisia do trânsito, com desperdício de tempo e combustível, além dos problemas ambientais de poluição atmosférica e de ocupação do espaço público.

Segundo o diretor Ricky Ribeiro, do Mobilize Brasil, a mobilidade urbana sustentável é a integração inteligente de vários modos de transporte urbano, com a maior eficiência e conforto possível para os passageiros, com o menor impacto ambiental para os espaços urbanos.

Alguns exemplos de modais urbanos sustentáveis envolvem a implantação de sistemas sobre trilhos, como metrôs, trens e bondes modernos (VLTs - Veículos Leves sobre Trilhos), ou podendo ser também ônibus "limpos", sendo estes, ônibus elétricos ou por biodiesel. Estes meios deverão ter integração com ciclovias, esteiras rolantes, entre outros, caso sejam necessários. E soluções inovadoras, como os teleféricos de Medellín (Colômbia), ou sistemas de bicicletas públicas, como os implantados em Paris, Barcelona, Boston e várias outras cidades mundiais. 
Por fim, a mobilidade urbana também demanda calçadas confortáveis, niveladas, sem buracos e obstáculos, porque um terço das viagens realizadas nas cidades brasileiras é feita a pé ou em cadeiras de rodas.

Segundo Malatesta (2012), Seul também se tornou referência, ao programar medidas voltadas à sustentabilidade, como a derrubada de uma via elevada sobre um rio canalizado. Acreditou na necessidade da mudança da matriz de mobilidade e investiu em programas que valorizam e estimulam modos de transporte não motorizados, em especial o modo de transporte a pé e por bicicleta, ao mesmo tempo em que valorizam a paisagem.
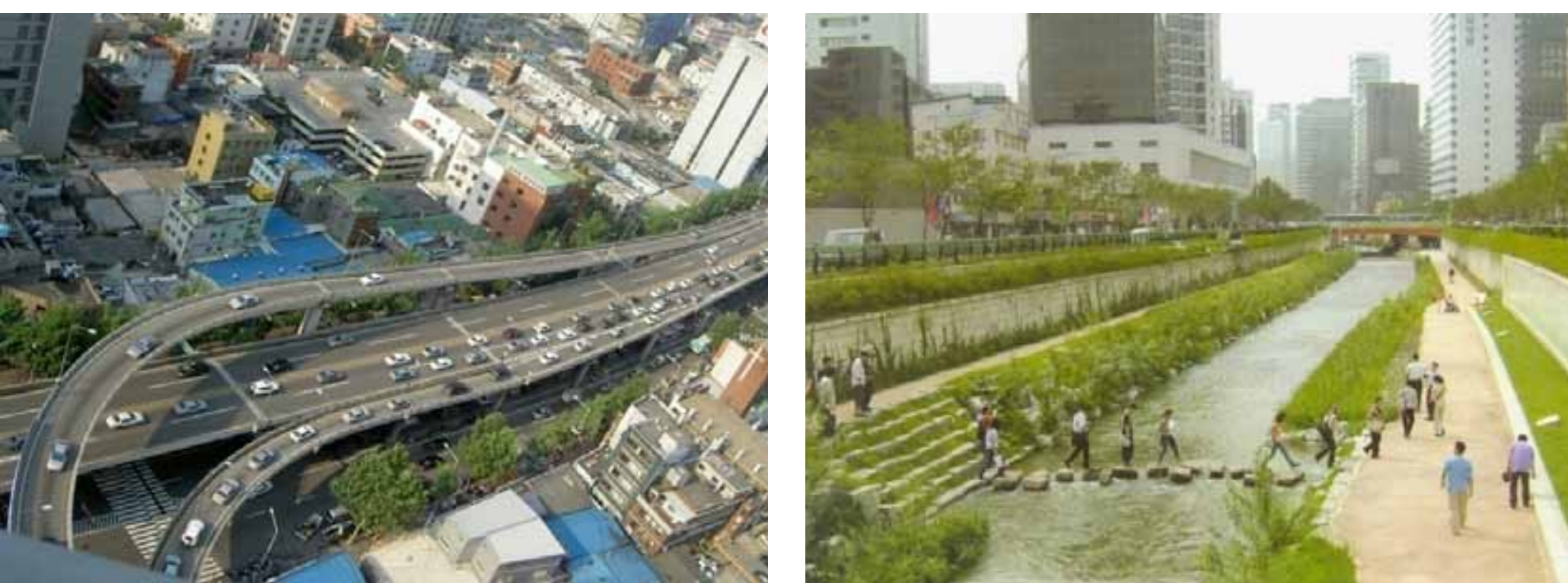

Figuras 19 e 20. Fotos: MALATESTA 2012.

\section{HIPÓTESES DE INFRAESTRUTURA VERDE PARA CRIAÇÃO DO PARQUE LINEAR BRÁS - LAPA}

Como hipóteses de infraestrutura verde para criação do parque linear, a pesquisadora contou com alguns artigos estudados, e outros que estavam sendo desenvolvidos ao longo da disciplina de pós-graduação Projeto Sustentável, da FAUUSP - Faculdade de Arquitetura e Urbanismo da Universidade de São Paulo, em agosto de 2012, que possibilitaram novos parâmetros e hipóteses para criação do parque linear Brás Lapa.Inicialmente, é importante relembrar que a área estudada trata-se de uma linha férrea da CPTM - Companhia Paulista de Trens Metropolitanos, que, na proposta da Operação Urbana Lapa - Brás, será enterrada em seus 12 quilômetros de extensão, 
tendo sobre ela uma avenida com canteiros, para melhorar a área verde da cidade.

Nos estudos de caso apresentados, nota-se a importância de se visualizar o meio de transporte originário do local, visualizando in loco e entendendo a historicidade e a integração entre pedestre e meio de modo geral, e isto não foi feito na proposta da Operação Urbana, muito pelo contrário, eles enterram totalmente a linha férrea, como um problema que deve ser ignorado.

Ainda de acordo com os estudos de caso, em todos aparece a figura bem marcada do histórico do local, ou, então, de sua passagem em partes.

Então, como se pode integrar o meio ambiente, o transporte e o pedestre?

São escalas muito distintas, e é preciso ter muito cuidado, para não se cometer um erro e acabar afastando ainda mais, ao invés de integrar.

Uma primeira hipótese seria a intervenção diretamente na linha férrea, ora tornado-a subterrânea, ora não, para garantir a relação desta com o meio, e fazer a interligação em nível com o pedestre e outros modais, garantindo, assim, um transporte ainda mais eficiente. Quando os diferentes modais se encontram, estes podem abastecer e melhorar a locomoção dos pedestres ao longo do entorno, enquanto o trem faz a ligação de longa distância entre a zona Leste e a zona Oeste, entre os bairros da Lapa e Brás.

Sobre as críticas feitas no item anterior, no levantamento da Operação Urbana Lapa - Brás, a pesquisadora nesta etapa vai levantar hipóteses para estas, seguindo a infraestrutura verde, para criação do parque linear Brás - Lapa, garantindo os conceitos abordados para o projeto sustentável.

\section{Hipóteses para implantar um conjunto de melhoramentos viários visando ligações de longo percurso.}

A primeira hipótese seria o enterramento de parte da linha férrea que faz o deslocamento mais longo, pois, quando esta se mantiver no nível, fará a ligação com outros modais que abastecerão o entorno próximo. Sobre a ferrovia, haverá o parque linear com faixa para caminhada de pedestres e ciclovias, bondes elétricos fazendo o transporte de trajetos curtos, além de equipamentos de lazer. 
Quando a linha férrea estiver em nível, o parque poderá se deslocar acima do solo, ou para as laterais da linha férrea, deixando-a descoberta. A importância de a linha férrea aparecer na paisagem é para mostrar sua relevância no local e demarcar as estações e interligações entre meios de transportes.

Hipóteses para melhorar os sistemas de macro e micro drenagem, para diminuir os problemas de inundação;

Trabalhando com um parque linear ao longo do eixo do trilho da CPTM - Companhia Paulista de Trens Metropolitanos, ora sobre a linha férrea, ora em suas laterais, pode-se aumentar a infraestrutura verde urbana ao longo do percurso, melhorando, assim, os sistemas de macro e micro drenagem, diminuindo, com isso, os problemas de inundação.

\section{Hipóteses para implantar espaços públicos;}

Na hipótese do parque linear, os espaços promovidos ao longo do percurso do trilho do trem tornam-se espaços de passagem, de troca de transporte, de lazer para a população, tornando-se espaços públicos também como área de permanência e áreas de melhorias de paisagem para o local de intervenção.

\section{Hipóteses para implantar equipamentos do interesse da comunidade;}

Por se tratar de uma área de interesse da comunidade, o espaço público que conta com áreas de permanência e áreas de lazer pode ainda contar, ao longo do percurso de caminhada, com equipamentos urbanos para estar e equipamentos urbanos, para utilização da população, visando a saúde e bem-estar, tornando o parque linear também atrativo àqueles que visam frequentar para manter a saúde e a boa forma, e não apenas àqueles que estão de passagem.

Hipóteses para promover a reestruturação e a requalificação urbanística e ambiental do território;

O parque linear e toda sua proposta de melhoria com circulação e transporte promo- 
verão que a infraestrutura funcione melhor na região. Com isso, o local poderá ser reestruturado, tanto urbanisticamente, quanto ambientalmente, considerando a infraestrutura verde proposta ao longo do parque linear.

Hipóteses para integrar os tecidos atualmente segregados pelo sistema sobre trilhos, ampliando as conexões entre os fluxos de circulação;

Com a hipótese de rebaixar parte do trilho, pode-se unir, através do parque linear, os bairros até então separados. A ideia é que o parque linear faça a ligação e mantenha, em certos pontos, as estações de trem em nível, interligando com outros modais e com o próprio parque, o que proporcionará um transporte leve local, facilitando e ampliando as conexões entre os fluxos de circulação.

Hipóteses para aumentar e promover a criação, ampliação e requalificação de áreas verdes e espaços livres de uso público, aumentando a permeabilidade e área verde, e locais de convivência e relações sociais;

A hipótese de criação de um parque linear ao longo dos 12 quilômetros do eixo da linha férrea Lapa - Brás, que estará ora subterrânea, e, portanto, com o parque sobre esta, ora em nível, e o parque linear ao lado desta, ou até mesmo promovendo uma superfície tipo HighLine sobre a linha férrea, promoverá a ampliação e, consequentemente, a requalificação das áreas verdes como objeto de intervenção, aumentando os espaços livres de uso público e áreas de convivência, como, também, aumentando a permeabilidade da cidade de São Paulo, que é sempre muito questionada, nas intervenções urbanas.

\section{CONSIDERAÇÕES FINAIS}

Neste estudo, a pesquisadora percebeu que nem sempre as propostas feitas pelos órgãos públicos são as melhores como solução para a cidade, ou, então, não vislumbram os objetivos que hoje fazem parte do principal conceito, que é tornar a cidade cada vez mais sustentável, para que não haja prejuízo para as gerações futuras.

A infraestrutura verde é essencial para manter uma cidade bem estruturada, organizada e delimitada, em que as pessoas sejam muito mais valorizadas do que os trans- 
portes, tendo sua integração direta com o meio ambiente e equipamentos essenciais para o seu dia a dia. A infraestrutura verde consiste em redes multifuncionais de fragmentos permeáveis e vegetados (preferencialmente arborizados), interconectados, reestruturando o mosaico da paisagem. Visa manter ou restabelecer os processos e fluxos naturais e culturais que asseguram a qualidade de vida urbana, segundo Herzog (2010), lembrando Benedict e McMahon (2006) e Ahern (2007).

Os estudos de caso sobre a mesma temática são essenciais para uma melhor proposta de intervenção, como diretrizes para o local.

Nenhuma medida deve ser tomada sem um mínimo de estudo, referencial teórico, análise do local e entorno. As consequências podem ser danosas e bem piores do que as encontradas até antes mesmo da intervenção.

\section{REFERÊNCIAS BIBLIOGRÁFICAS}

CORMIER, Nathaniel S.; PELLEGRINO, Paulo Renato Mesquita. Infraestrutura verde: Uma estratégia paisagística para a água urbana. Revista Paisagem e Ambiente - Ensaios, São Paulo, n. 25, 2008.

FERREIRA, José Carlos; MACHADO, João Reis. Infraestruturas verdes para um futuro urbano sustentável. O contributo da estrutura ecológica e dos corredores verdes. Revista LabVerde, São Paulo, n. 1, 2010.

FRANCO, M. A. R. Desenho ambiental: Uma introdução à arquitetura da paisagem com o paradigma ecológico. 2 ed. São Paulo: Annablume, 2008.

. Planejamento ambiental para a cidade sustentável. São Paulo: Annablume, 2001.

FRIEDRICH, Daniela. A visão ambiental no planejamento e gestão de parques lineares em áreas de fundo de vale urbana. In: $O$ parque linear como instrumento de planejamento e gestão das áreas de fundo de vale urbanas. Dissertação (Mestrado em Planejamento Urbano e Regional) - Faculdade de Arquitetura, Universidade Federal do Rio Grande do Sul. Porto Alegre, 2007. p.66-100. 
HERZOG, Cecília P. Infraestrutura verde, sustentabilidade e resiliência urbana. Revista InVerde, São Paulo, 2010.

HOUGH, Michael. Naturaleza y ciudad: Planificación urbana y processos ecológicos. Barcelona: Gustavo Gili, 1998.

MALATESTA, Maria Ermelina Brosch. Andar a pé: Um modo de transporte para a cidade de São Paulo. Dissertação (Mestrado) - FAUUSP. São Paulo, 2008.

SÃO PAULO (Município). Secretaria Municipal de Planejamento Urbano/Secretaria Municipal do Verde e Meio Ambiente. Atlas ambiental do município de São Paulo. São Paulo, 2002.

SÃO PAULO (Estado). Secretaria do Meio Ambiente/Secretaria Municipal de Planejamento. Vegetação significativa do município de São Paulo. São Paulo, 1988.

. Secretaria do Meio Ambiente. Instrumentos legais necessários à implantação de parques lineares. São Paulo, 2006.

VALERI S. V., SENÔ M. A. A. F. A importância dos corredores ecológicos para a fauna e a sustentabilidade de remanescentes florestais. Teses Independentes Unesp, 2004.

OPERAÇÃO URBANA CONSORCIADA LAPA-BRÁS (sites de busca e análise)

http://www.prefeitura.sp.gov.br/cidade/secretarias/upload/chamadas/trouc_lapa-bras versao_consulta_publica_1289322011.pdf <acessado em 19 de outubro de 2012>

http://blog.al.com/businessnews/2012/10/post_183.html. <acessado em 26 de outubro de 2012>

http://blog.mundi.com.br/2012/08/20/high-line-\%E-um-exemplo-de-urbanismosustentavel-em-nova-york/ <acessado em 26 de outubro de 2012>

http://blog.naturaekos.com.br/ruinastrilhotremviramparqueecologicoperu/<acessado 26 de outubro de 2012> 
http://www.diariodalapa.com.br/noti_lapa/lapabras_edital911.htm. <acessado em 02 de novembro de 2012>

http://www.estadao.com.br/fotos/NO_TEXTlapa_600.jpg. <acessado em 02 de novembro de 2012>

http://www.estadao.com.br/noticias/cidades, prefeitura-quer-tunel-de-12-km-paracirculacao-de-trens-entre-lapa-e-bras. <acessado em 26 de outubro de 2012>

http://www.googlemaps.com <acessado em 12 de outubro de 2012>

http://www.governing.com/columns/urban-notebook/col-railroad-park-unites-birminghamalabama.html. <acessado em 26 de outubro de 2012>

http://www.ideosfera.ggf.br/wp-content/uploads/2011/06/CPTM-Opera-Urbana-LapaBr\%C3\%A1s-01.png. <acessado em 02 de novembro de 2012>

http://www.mobilize.org.br/sobre-o-portal/mobilidade-urbana-sustentavel/<acessado 26 de outubro de 2012>

http://www.railroadpark.org/ <acessado em 26 de outubro de 2012>

http://sementesustentavel.blogspot.com.br/2012/04/um-parque-nos-trilhos-do trem. html\#!/2012/04/um-parque-nos-trilhos-do-trem.html. <acessado em 26 de outubro de 2012>http://www.tomleader.com/ <acessado em 26 de outubro de 2012> 